\title{
The importance of dietary antioxidants on plasma antioxidant capacity and lipid peroxidation in vivo in middle-aged men
}

\author{
Cecilia Nälsén', Samar Basu', Alicja Wolk² and Bengt Vessby' \\ 'Clinical Nutrition and Metabolism, Department of Public Health and Caring Sciences, Uppsala University, Uppsala, \\ Sweden ${ }^{2}$ Division of Nutritional Epidemiology, The National Institute of Environmental Medicine, Karolinska Institutet, \\ Stockholm, Sweden
}

\section{Abstract}

Background: High intake of foods rich in antioxidants is associated with a reduced risk of several diseases, including coronary heart disease and some cancers.

Objective: To study associations between dietary antioxidants and antioxidant-rich food items and antioxidant capacity (AOC), as well as lipid peroxidation in vivo.

Design: A total of 86 men, with a mean age of 60 years, who were part of a larger population-based study in Sweden, participated. Fourteen $24 \mathrm{~h}$ recalls were collected by telephone, evenly distributed during 1 year. AOC was measured in plasma using an enhanced chemiluminescence assay and biomarkers of non-enzymic in vivo lipid peroxidation were determined by measuring $\mathrm{F}_{2}$-isoprostanes (8-iso-prostaglandin $\left.\mathrm{F}_{2 \alpha}\right)$ in plasma. Results: Higher intakes of ascorbic acid, tocopherols and $\beta$-carotene, and of the combined intake of different antioxidant-rich foods, were related to a higher plasma AOC. The levels of $\mathrm{F}_{2}$-isoprostanes were related neither to dietary intake of antioxidants nor to antioxidant-rich foods.

Conclusions: Individuals with a higher intake of several different antioxidant-rich foods and of dietary antioxidants had a higher plasma AOC than those with the lowest intake, supporting the importance of a balanced diet rich in various antioxidants. Moreover, the results indicate that non-enzymic lipid peroxidation in vivo, measured as $\mathrm{F}_{2}$-isoprostanes in plasma, is not easily affected by the diet.

Keywords: antioxidant status; diet; food habits; isoprostanes; oxidative stress

Received: 23 Jan. 2006; Revised: 2 Mar. 2006; Accepted: 20 Mar. 2006

\section{Introduction}

A high intake of foods rich in antioxidants is associated with a reduced risk of several diseases, including coronary heart disease and some cancers (1-3). Since antioxidants are suggested to interact in a complex network, measurement of antioxidant capacity (AOC) in plasma may be a good approach by which to study the integrated effect of a number of antioxidants in humans in vivo. Several methods have been developed to measure the AOC of different foods, as well as in plasma or serum (4$8)$. Recent studies have reported the AOC of various foods $(9,10)$ and others have calculated AOC in the diet (11-13), but studies investigating the effect of food habits or long-term food intake on plasma AOC are sparse $(14,15)$.

Oxidative stress is a condition with increased production of free radicals or reactive oxygen species associated with reduced antioxidant defence, which might lead to different types of oxidative damage in the body and contribute to the development of several chronic diseases (16). Oxidative stress can be assessed by measuring lipid peroxidation in the body. When lipid peroxidation in the body is increased, the antioxidant levels may be either reduced owing to an increased consumption or increased owing to an up-regulation of the endogenous antioxidant production $(17,18)$. It is of interest to investigate further the impact of dietary factors on the AOC and biomarkers of lipid peroxidation in vivo.

This study investigated the associations between dietary antioxidants (ascorbic acid, tocopherols and $\beta$-carotene) and antioxidant-rich foods, and AOC and non-enzymic lipid peroxidation in vivo, 
measured as $\mathrm{F}_{2}$-isoprostanes, in plasma in middleaged men.

\section{Subjects and methods}

A total of 86 apparently healthy men, who took part in a large population-based study in central Sweden, was included in the study. None of the subjects was taking dietary supplements. Nineteen were current smokers. The study was approved by the Ethics Committee of the Faculty of Medicine at Uppsala University.

\section{Dietary assessment}

For each participant, fourteen $24 \mathrm{~h}$ recalls were collected by telephone during a period of 1 year. Each participant was interviewed approximately once a month, and every day of the week was covered twice in a random order. An average daily intake of foods, food groups and beverages rich in antioxidants - fruits and berries, vegetables, root vegetables, leguminous plants, tea, coffee, red wine, white wine, juices, jam and marmalade was calculated. The database from the Swedish National Food Administration (PC-Kost 1996; SLV, Uppsala, Sweden) was used for calculation of the nutrients in the $24 \mathrm{~h}$ recalls. Intake of ascorbic acid, tocopherols and $\beta$-carotene was calculated, as well as the density of these antioxidants per $1000 \mathrm{kcal}$.

\section{Blood sampling}

Blood samples were taken from an antecubital vein after an overnight fast. All plasma or serum samples were kept frozen at $-70^{\circ} \mathrm{C}$ until analysed, or fresh samples were used.

\section{Biochemical analyses}

The plasma AOC was measured using an enhanced chemiluminescence assay (5). This technique is based on the measurement of light emission from a chemiluminescent substrate, which is suppressed by radical scavenging antioxidants, and the duration of light suppression is related to the amount of antioxidant present. Light emissions from the chemiluminescent reaction were measured with a luminometer (1251 Luminometer; BioOrbit, Turku, Finland). Antioxidant capacities of samples were quantified by comparing the duration of light suppression to that induced by the tocopherol analogue Trolox (Aldrich Chemie, Steinheim, Germany). The concentration is expressed in $\mu \mathrm{mol}$ Trolox equivalents per litre of plasma. Plasma AOC in the absence of uric acid was determined by adding uricase (Boehringer, Mannheim, Germany) to remove the uric acid content in the plasma sample before measuring the AOC. The coefficient of variation between duplicate plasma samples was $3.2 \%$. AOC without uric acid is partly correlated with the concentration of plasma lipids, probably reflecting the transport of lipid-soluble antioxidants by lipid molecules. Therefore, the AOC was also calculated with and without adjustment for the sum of cholesterol and triglycerides in serum (AOC without uric acid divided with sum of cholesterol and triglyceride concentrations in serum), as tocopherol concentration is often expressed (19). The concentration of uric acid in plasma was measured enzymically (Instrumentation Laboratories, Lexington, MA, USA) in a Monarch centrifugal analyser (Instrumentation Laboratories). The coefficient of variation between duplicate plasma samples was $1.4 \%$.

The plasma levels of 8-iso-prostaglandin $\mathrm{F}_{2 \alpha}$ (8-iso-PGF $\mathrm{P}_{2 \alpha}$ ) was analysed using a validated radioimmunoassay developed by Basu (20). The detection limit of the assay was $8 \mathrm{pg} \mathrm{ml}^{-1}$.

The concentrations of cholesterol and triglycerides in serum and in the isolated lipoprotein fractions were determined by enzymic colorimetric methods (Instrumentation Laboratories) in a Monarch centrifugal analyser (Instrumentation Laboratories). Low-density lipoprotein (LDL) cholesterol was calculated according to Friedewald (21).

\section{Statistics}

Variables with a skewed distribution (Shapiro Wilk's $W$-test $<0.95$ ) were log-transformed before statistical analysis. Otherwise, non-parametric tests were used. The Student's unpaired $t$-test or MannWhitney test was used to analyse differences in AOC between the mean of the three highest quartiles and the lowest one. This calculation is based on results from a previous study, which found that only subjects with the lowest AOC exhibited a significant increase after intake of foods rich in antioxidants (unpublished observations). For $\mathrm{F}_{2}$-isoprostanes the difference between the lowest and the highest quartile was tested. The correlation coefficients (Pearson's or Spearman's as appropriate) were calculated when correlations between variables were tested. $p$-Values $<0.05$ were regarded 
as statistically significant. Statistical analyses were performed using JMP, version 3.2 (SAS Institute, Cary, NC, USA).

\section{Results}

The clinical characteristics of the study participants are shown in Table 1 and the estimated dietary intake of macronutrients, antioxidants and antioxidant-rich foods is shown in Table 2.

The summarised intake of ascorbic acid, tocopherols and $\beta$-carotene was higher in the three upper quartiles of AOC than in the lowest quartile, as shown in Table 3. A higher intake of ascorbic acid was related to higher levels of AOC, whereas the associations for tocopherols and $\beta$-carotene were weaker, when considered separately. A significant difference in intake of foods between the lowest and the higher quartiles of AOC was found only when different food groups were combined (Table 4). No relationship was found between the intake of tea and coffee, and AOC. The combined intake of ascorbic acid, tocopherols and $\beta$-carotene [mean (SD), mg $1000 \mathrm{kcal}^{-1}$ ] related to quartiles of AOC was, in quartile 1: 32 (10); quartile 2: 45 (15); quartile 3: 42 (16); and quartile 4: 42 (16), and the combined intake of fruits, berries, vegetables and root vegetables ( $\mathrm{g}$ per day) as related to quartiles of AOC was, in quartile 1: 151 (72); quartile 2: 225 (85); quartile 3: 185 (68); and quartile 4: 190 (125). Furthermore, intake of food groups calculated per $1000 \mathrm{kcal}$ per day showed a

Table I. Characteristics of study participants

\begin{tabular}{|c|c|}
\hline & $\begin{array}{l}\text { Mean (SD) } \\
(n=86)\end{array}$ \\
\hline Age (years) & $59.8(8.1)$ \\
\hline BMI $\left(\mathrm{kg} \mathrm{m}^{2}\right)$ & $26.5(2.9)$ \\
\hline Total cholesterol $\left(\mathrm{mmol} \mathrm{I}^{-1}\right)$ & $5.92(1.13)$ \\
\hline $\mathrm{HDL}$ cholesterol $\left(\mathrm{mmol} \mathrm{I}^{-1}\right)$ & $1.27(0.35)$ \\
\hline LDL cholesterol $\left(\mathrm{mmol} \mathrm{I}^{-1}\right)$ & $4.02(0.98)$ \\
\hline LDL/HDL & $3.35(1.06)$ \\
\hline Triglycerides $\left(\mathrm{mmol} \mathrm{I}^{-1}\right)$ & $1.40(0.70)$ \\
\hline AOC ( $\mu$ mol Trolox equivalents $\mathrm{I}^{-1}$ ) & $487.1(80.5)$ \\
\hline AOC without uric acid ( $\mu$ mol Trolox equivalents $\left.I^{-1}\right)$ & $104.5(23.2)$ \\
\hline Uric acid $\left(\mu \mathrm{mol} \mathrm{I}{ }^{-1}\right)$ & $276.1(61.5)$ \\
\hline $\begin{array}{l}\text { Lipid-adjusted AOC without uric acid ( } \mu \text { mol Trolox equivalents } \\
\left.I^{-1}\right)\end{array}$ & $14.49(2.75)$ \\
\hline $\mathrm{F}_{2}$-isoprostanes $\left(\mathrm{pg} \mathrm{ml}^{-1}\right)$ & $32.5(23.1)$ \\
\hline
\end{tabular}

Data are presented as means (SD).

BMI: body mass index; HDL: high-density lipoprotein; LDL: low-density lipoprotein; AOC: antioxidant capacity.
Table 2. Mean daily dietary intake of selected nutrients and foods based on fourteen $24 \mathrm{~h}$ recalls in the 86 men in the study

\begin{tabular}{|c|c|}
\hline & Mean (SD) \\
\hline \multicolumn{2}{|l|}{ Nutrients } \\
\hline Energy (kcal) & $2088(40 I)$ \\
\hline Protein $(E \%)$ & $14.9(2.1)$ \\
\hline Carbohydrate $(E \%)$ & $47.6(5.4)$ \\
\hline Fat $(E \%)$ & $33.4(3.8)$ \\
\hline SFA $(E \%)$ & $14.2(2.1)$ \\
\hline MUFA (E\%) & $12.1(1.5)$ \\
\hline PUFA (E\%) & $4.9(0.9)$ \\
\hline Alcohol $(E \%)$ & $4.2(4.3)$ \\
\hline Ascorbic acid (mg) & $72.9(30.3)$ \\
\hline Tocopherols (mg) & $7.8(1.6)$ \\
\hline$\beta$-Carotene (mg) & $2.2(1.6)$ \\
\hline \multicolumn{2}{|l|}{ Food groups } \\
\hline Fruits and berries $(\mathrm{g})$ & $123(78)$ \\
\hline Vegetables (g) & $54(32)$ \\
\hline Root vegetables $(\mathrm{g})$ & II (14) \\
\hline Leguminous plants $(\mathrm{g})$ & $3(\mathrm{II})$ \\
\hline Fruits and berries + vegetables + root vegetables $(\mathrm{g})$ & $188(92)$ \\
\hline Black tea $(\mathrm{g})$ & $153(231)$ \\
\hline Coffee $(\mathrm{g})$ & $463(234)$ \\
\hline Red wine $(g)$ & $25(39)$ \\
\hline White wine(g) & $20(39)$ \\
\hline Juices $(g)$ & $29(59)$ \\
\hline Jam/marmalade $(\mathrm{g})$ & $15(14)$ \\
\hline Total intake of selected foods excluding tea and coffee $(g)^{a}$ & $279(145)$ \\
\hline
\end{tabular}

SFA: saturated fatty acids; MUFA: monounsaturated fatty acids; PUFA: polyunsaturated fatty acids.

${ }^{\text {aS }}$ um of daily intake of fruit and berries, vegetables, root vegetables, leguminous plants, red wine, white wine, juices, and jam and marmalade.

similar pattern, with a difference between the lowest and the higher quartiles (for fruits, berries, vegetables and root vegetables, $p<0.01$, and for total intake of selected foods excluding tea and coffee, $p<0.001$ ).

The relationships between dietary intake and AOC, when uric acid was removed and adjusted for lipid concentration, were similar, but the differences were smaller and there were no significant differences between the higher and lowest quartiles (results not shown).

The relationship between the intake of ascorbic acid and AOC without uric acid was $r=0.20, p=$ 0.065 , and between the combined intake of ascorbic acid, tocopherols and $\beta$-carotene $r=0.21, p=0.056$, and the intake of $\beta$-carotene was significantly correlated with AOC without uric acid $(r=0.25$, $p<0.05$ ).

AOC without uric acid was not significantly correlated with any of the food groups, but lipid- 
Table 3. Nutrient density of selected dietary antioxidants by quartiles of plasma antioxidant capacity (AOC) in the 86 men in the study

\begin{tabular}{|c|c|c|c|c|c|}
\hline & \multirow{2}{*}{$\begin{array}{l}\text { Quartile I (lowest) of AOC, } 327-423 \\
\left(\mu \mathrm{mol} \text { Trolox equivalents } \mathrm{I}^{-1}\right) \\
(n=2 \mathrm{I})\end{array}$} & \multirow{2}{*}{$\begin{array}{l}\text { Quartiles } 2-4 \text { of AOC, } 424-675 \\
\left(\mu \mathrm{mol} \text { Trolox equivalents } \mathrm{I}^{-1}\right) \\
(n=65)\end{array}$} & \multirow[t]{2}{*}{$\begin{array}{l}P \text { for difference between lowest } \\
\text { and three higher quartiles of } A O C\end{array}$} & \multicolumn{2}{|c|}{$\begin{array}{l}\text { Correlation } \\
\text { with AOC }\end{array}$} \\
\hline & & & & $r$ & $P$ \\
\hline Ascorbic acid (mg $\left.1000 \mathrm{kcal}^{-1}\right)$ & $27.8(9.5)$ & $38.1(15.5)$ & 0.006 & 0.24 & 0.026 \\
\hline Tocopherols (mg $1000 \mathrm{kcal}^{-1}$ ) & $3.7(0.8)$ & $3.8(0.5)$ & 0.198 & 0.19 & 0.086 \\
\hline$\beta$-carotene $\left(\mathrm{mg} 1000 \mathrm{kcal}^{-1}\right)$ & $0.91(0.61)$ & $1.12(0.77)$ & 0.135 & 0.12 & 0.274 \\
\hline $\begin{array}{l}\text { Ascorbic acid + tocopherols }+ \\
\quad \beta \text {-carotene }\left(\mathrm{mg} 1000 \mathrm{kcal}^{-1}\right)\end{array}$ & $32.3(9.7)$ & $43.1(15.8)$ & 0.005 & 0.25 & 0.021 \\
\hline
\end{tabular}

Data are presented as means (SD).

adjusted AOC without uric acid was correlated with intake of vegetables $(r=0.23, p<0.05)$, intake of root vegetables $(r=0.34, p<0.01)$, and total intake of selected foods excluding tea and coffee $(r=0.24$, $p<0.05)$. The intake of vegetables was significantly higher in the higher quartiles of lipid-adjusted AOC without uric acid than in the lowest quartile $(p<$ $0.05)$.

There were no associations between the levels of $\mathrm{F}_{2}$-isoprostanes and intake of ascorbic acid, tocopherols or $\beta$-carotene, either when considered separately or when combined. None of the studied food groups was correlated with $\mathrm{F}_{2}$-isoprostanes. However, subjects in the lowest quartile of $\mathrm{F}_{2}$-isoprostanes had a higher intake of white wine compared with subjects in the highest quartile, with a significant difference between the lowest and the highest quartile $(p<0.05)$.
There was no significant correlation between $\mathrm{AOC}$ and $\mathrm{F}_{2}$-isoprostanes or between $\mathrm{AOC}$ without uric acid and $\mathrm{F}_{2}$-isoprostanes.

Furthermore, the concentration of uric acid was not correlated with intake of ascorbic acid, tocopherols or $\beta$-carotene or with any of the food groups.

Intake of ascorbic acid was correlated with intake of fruits and berries $(r=0.54, p<0.0001)$ and vegetables $(r=0.26, \quad p<0.05)$, and intake of $\beta$-carotene was correlated with intake of root vegetables $(r=0.77, \quad p<0.0001)$ and vegetables $(r=0.31, p<0.01)$.

\section{Discussion}

A higher dietary intake of ascorbic acid, tocopherols and $\beta$-carotene, when considered together, as well as a higher dietary intake of ascorbic acid, was

Table 4. Daily consumption of antioxidant-rich foods by quartiles of plasma antioxidant capacity (AOC) in the 86 men in the study

\begin{tabular}{|c|c|c|c|c|c|}
\hline & \multirow{2}{*}{$\begin{array}{l}\text { Quartile I (lowest) of AOC, } 327-423 \\
\left(\mu \mathrm{mol} \text { Trolox equivalents } \mathrm{I}^{-1}\right) \\
(n=2 \mathrm{I})\end{array}$} & \multirow{2}{*}{$\begin{array}{l}\text { Quartiles } 2-4 \text { of } A O C, 424-675 \\
\left(\mu \text { mol Trolox equivalents } I^{-1}\right) \\
(n=65)\end{array}$} & \multirow[t]{2}{*}{$\begin{array}{l}P \text { for difference between lowest } \\
\text { and three higher quartiles of } A O C\end{array}$} & \multicolumn{2}{|c|}{$\begin{array}{l}\text { Correlation } \\
\text { with AOC }\end{array}$} \\
\hline & & & & $r$ & $p$ \\
\hline Fruits and berries $(\mathrm{g})$ & $96(55)$ & $132(83)$ & 0.097 & 0.04 & 0.740 \\
\hline Vegetables (g) & $46(27)$ & $56(33)$ & 0.133 & 0.09 & 0.420 \\
\hline Root vegetables (g) & $9(12)$ & $12(15)$ & 0.763 & 0.09 & 0.478 \\
\hline Leguminous plants (g) & $3(8)$ & $4(18)$ & 0.295 & 0.06 & 0.678 \\
\hline $\begin{array}{l}\text { Fruits and berries }+ \text { vegetables }+ \\
\text { root vegetables }(\mathrm{g})\end{array}$ & $|5|(72)$ & $200(95)$ & 0.016 & 0.12 & 0.278 \\
\hline Black tea $(g)$ & $152(165)$ & $153(250)$ & 0.637 & -0.13 & 0.225 \\
\hline Coffee $(g)$ & $507(223)$ & $448(237)$ & 0.069 & -0.08 & 0.446 \\
\hline Red wine $(g)$ & $14(26)$ & $28(42)$ & 0.180 & 0.11 & 0.335 \\
\hline White wine $(\mathrm{g})$ & $10(23)$ & $24(42)$ & 0.602 & 0.27 & 0.134 \\
\hline Juices (g) & II (2I) & $34(66)$ & 0.183 & 0.21 & 0.055 \\
\hline Jam/marmalade (g) & $20(19)$ & $13(12)$ & 0.272 & 0.15 & 0.208 \\
\hline $\begin{array}{l}\text { Total intake of selected foods } \\
\text { excluding tea and coffee }(\mathrm{g})\end{array}$ & $210(87)$ & $302(153)$ & 0.005 & 0.19 & 0.074 \\
\hline
\end{tabular}

Data are presented as means (SD). 
associated with a higher plasma AOC. Similarly, a significant association between antioxidant-rich foods and AOC was apparent when a number of antioxidant-rich food groups was considered together. These findings may support the synergistic and integrated effects between different types of antioxidants, and the importance of a variety of antioxidants from different food sources for the AOC in plasma.

The AOC in various foods can differ enormously, by more than a 1000 -fold (9). Berries generally have high antioxidant capacities $(9,10)$, but the difference in intake of fruit and berries between the lowest and the three higher quartiles of AOC did not differ significantly in the present study. However, when intakes of vegetables and root vegetables were considered together with intake of fruits and berries, there was a significant difference in intake between the lowest and the higher quartiles of AOC. Halvorsen and co-workers reported that fruits and berries in a Norwegian diet contributed most to the total intake of plant antioxidants, but beverages were not included in these calculations (9). Beverages such as tea, wine and coffee also have high antioxidant capacities, owing to a high content of polyphenols and other phenolic compounds. Thus, although a high AOC in beverages such as tea, coffee and wine is reported (10), as well as increases in AOC after intake (22-24), this was not reflected in the AOC measured in plasma in this study.

AOC in plasma is affected not only by exogenous antioxidants from the diet, but also by endogenous antioxidants such as uric acid and bilirubin, as well as by ongoing oxidation processes in the body. In most of the AOC assays, uric acid is a major contributor, with clear correlations between AOC and uric acid content $(25,26)$, but the function of uric acid as an antioxidant is unclear. In a previous study, therefore, uricase was used to remove uric acid in the sample (in press). In this study a similar pattern was found, with an association between higher intakes of antioxidants and antioxidant-rich foods and higher levels of AOC, also when uric acid was removed. AOC without uric acid was also correlated with the intake of $\beta$-carotene, as well as with the intake of vegetables and root vegetables, which are the most important sources of $\beta$-carotene in Sweden (27).

In the present study the AOC in plasma was measured. This depends on the intake, as well as on the bioavailability, of the dietary antioxidants. The associations between AOC in plasma and dietary factors were also studied. Others have calculated the AOC in the diet, which does not account for the bioavailability of different antioxidants (11-13). Both food groups and nutrients were investigated, since the well-known antioxidants including ascorbic acid, $\alpha$-tocopherol and $\beta$-carotene are suggested to reflect only a minor part of the dietary antioxidants. However, cereals, nuts and spices, which may also contribute to the AOC, were not included in this study.

The plasma concentration of $\mathrm{F}_{2}$-isoprostanes is considered as a gold-standard indicator of lipid peroxidation in vivo $(28,29) . F_{2}$-isoprostanes are increased in clinical conditions associated with increased oxidative stress, such as diabetes (30, $31)$, and in smokers $(32,33)$. The results of this study showed that there were no differences in plasma $\mathrm{F}_{2}$-isoprostane concentrations when related to quartiles of ascorbic acid, tocopherols or $\beta$ carotene intake, or when they were combined. Reduced levels of $F_{2}$-isoprostanes were not seen in groups reporting a high intake of foods rich in antioxidants, which is in line with other studies $(34,35)$. In contrast, Block and co-workers reported an inverse correlation between plasma $\mathrm{F}_{2}$-isoprostanes and fruit intake (36). Results from intervention studies, where fruits and vegetables were added to the diet, have reported conflicting findings, with unaltered $(34,35)$ as well as decreased $(17,37)$ levels of $\mathrm{F}_{2}$-isoprostanes. However, in the present study, subjects in the lowest quartile of $\mathrm{F}_{2}$-isoprostanes had a higher intake of white wine, which is compatible with the high content of polyphenols in wine possibly decreasing the levels of $\mathrm{F}_{2}$-isoprostanes. Although the AOC is higher in red wine than in white wine (10), reflecting the higher content of polyphenols in red wine, which might decrease further the formation of $\mathrm{F}_{2}$-isoprostanes, this was not reflected in the current study. The relationships between dietary antioxidants and isoprostanes are complex (38) and the biological variation between individuals and day-to-day variation in $\mathrm{F}_{2}$-isoprostanes is high $(39,40)$.

A strength of this study was the use of repeated $24 \mathrm{~h}$ recalls, including every day of the week, twice. A limitation of the study was that blood samples were collected on only one occasion.

In summary, the results of this study showed that individuals with a higher intake of various 
antioxidant-rich foods, including different antioxidants, had a better plasma AOC. The associations tended to be stronger between plasma AOC and different antioxidant-rich foods, when the foods were combined. An optimal antioxidant status may be achieved by eating a balanced diet rich in a mix of various antioxidant-containing foods. Moreover, the results indicate that lipid peroxidation in vivo is not easily affected by the diet.

\section{Acknowledgements}

We thank all participants, and co-workers at the Metabolic Ward and Clinical Nutrition Research Laboratory.

\section{References}

1. Hertog MG, Kromhout D, Aravanis C, Blackburn H, Buzina R, Fidanza F, et al. Flavonoid intake and longterm risk of coronary heart disease and cancer in the seven countries study. Arch Intern Med 1995; 155: 381-6.

2. Knekt P, Reunanen A, Jarvinen R, Seppanen R, Heliovaara M, Aromaa A. Antioxidant vitamin intake and coronary mortality in a longitudinal population study. Am J Epidemiol 1994; 139: 1180-9.

3. Liu S, Manson JE, Lee IM, Cole SR, Hennekens CH, Willett WC, et al. Fruit and vegetable intake and risk of cardiovascular disease: the Women's Health Study. Am J Clin Nutr 2000; 72: 922-8.

4. Wayner DD, Burton GW, Ingold KU, Locke S. Quantitative measurement of the total, peroxyl radical-trapping antioxidant capability of human blood plasma by controlled peroxidation. The important contribution made by plasma proteins. FEBS Lett 1985; 187: 33-7.

5. Whitehead TP, Thorpe GHG, Maxwell SRJ. Enhanced chemiluminescent assay for antioxidant capacity in biological fluids. Anal Chim Acta 1992; 266: 265-77.

6. Cao G, Alessio HM, Cutler RG. Oxygen-radical absorbance capacity assay for antioxidants. Free Radic Biol Med 1993; 14: 303-11.

7. Miller NJ, Rice-Evans C, Davies MJ, Gopinathan V, Milner A. A novel method for measuring antioxidant capacity and its application to monitoring the antioxidant status in premature neonates. Clin Sci (Lond) 1993; 84: 407-12.

8. Benzie IF, Strain JJ. The ferric reducing ability of plasma (FRAP) as a measure of "antioxidant power": the FRAP assay. Anal Biochem 1996; 239: 70-6.

9. Halvorsen BL, Holte K, Myhrstad MC, Barikmo I, Hvattum E, Remberg SF, et al. A systematic screening of total antioxidants in dietary plants. J Nutr 2002; 132: 461-71.

10. Pellegrini N, Serafini M, Colombi B, Del Rio D, Salvatore S, Bianchi M, et al. Total antioxidant capacity of plant foods, beverages and oils consumed in Italy assessed by three different in vitro assays. J Nutr 2003; 133: 2812-9.

11. Cao G, Booth SL, Sadowski JA, Prior RL. Increases in human plasma antioxidant capacity after consumption of controlled diets high in fruit and vegetables. Am J Clin Nutr 1998; 68: 1081-7.

12. Serafini M, Bellocco R, Wolk A, Ekstrom AM. Total antioxidant potential of fruit and vegetables and risk of gastric cancer. Gastroenterology 2002; 123: 985-91.

13. Pulido R, Hernandez-Garcia M, Saura-Calixto F. Contribution of beverages to the intake of lipophilic and hydrophilic antioxidants in the Spanish diet. Eur J Clin Nutr 2003; 57: 1275-82.

14. Pitsavos C, Panagiotakos DB, Tzima N, Chrysohoou C, Economou M, Zampelas A, et al. Adherence to the Mediterranean diet is associated with total antioxidant capacity in healthy adults: the ATTICA study. Am J Clin Nutr 2005; 82: 694-9.

15. Szeto YT, Kwok TC, Benzie IF. Effects of a long-term vegetarian diet on biomarkers of antioxidant status and cardiovascular disease risk. Nutrition 2004; 20: 863-6.

16. Sies H. Oxidative stress: from basic research to clinical application. Am J Med 1991; 91: 31-8S.

17. Thompson HJ, Heimendinger J, Sedlacek S, Haegele A, Diker A, O'Neill C, et al. 8-Isoprostane F2alpha excretion is reduced in women by increased vegetable and fruit intake. Am J Clin Nutr 2005; 82: 768-76.

18. Jacob RA, Aiello GM, Stephensen CB, Blumberg JB, Milbury PE, Wallock LM, et al. Moderate antioxidant supplementation has no effect on biomarkers of oxidant damage in healthy men with low fruit and vegetable intakes. J Nutr 2003; 133: 740-3.

19. Thurnham DI, Davies JA, Crump BJ, Situnayake RD, Davis M. The use of different lipids to express serum tocopherol:lipid ratios for the measurement of vitamin $\mathrm{E}$ status. Ann Clin Biochem 1986; 23: 514-20.

20. Basu S. Radioimmunoassay of 8-iso-prostaglandin F2alpha: an index for oxidative injury via free radical catalysed lipid peroxidation. Prostaglandins Leukot Essent Fatty Acids 1998; 58: 319-25.

21. Friedewald WT, Levy RI, Fredrickson DS. Estimation of the concentration of low-density lipoprotein cholesterol in plasma, without use of the preparative ultracentrifuge. Clin Chem 1972; 18: 499-502.

22. Serafini M, Laranjinha JA, Almeida LM, Maiani G. Inhibition of human LDL lipid peroxidation by phenolrich beverages and their impact on plasma total antioxidant capacity in humans. J Nutr Biochem 2000; 11: 585-90.

23. Cao G, Russell RM, Lischner N, Prior RL. Serum antioxidant capacity is increased by consumption of strawberries, spinach, red wine or vitamin C in elderly women. J Nutr 1998; 128: 2383-90.

24. Natella F, Nardini M, Giannetti I, Dattilo C, Scaccini C. Coffee drinking influences plasma antioxidant capacity in humans. J Agric Food Chem 2002; 50: 6211-6.

25. Maxwell SR, Thomason H, Sandler D, Leguen C, Baxter MA, Thorpe GH, et al. Antioxidant status in patients with uncomplicated insulin-dependent and 
non-insulin-dependent diabetes mellitus. Eur $\mathbf{J}$ Clin Invest 1997; 27: 484-90.

26. Wayner DD, Burton GW, Ingold KU, Barclay LR, Locke SJ. The relative contributions of vitamin E, urate, ascorbate and proteins to the total peroxyl radicaltrapping antioxidant activity of human blood plasma. Biochim Biophys Acta 1987; 924: 408-19.

27. Becker W. Befolkningens kostvanor och näringsintag i Sverige 1989. Metod och resultatanalys (Food habits and nutrient intake in Sweden 1989). Uppsala: National Food Administration, Sweden; 1994. (In Swedish with English summary.)

28. Morrow JD, Hill KE, Burk RF, Nammour TM, Badr KF, Roberts LJ II. A series of prostaglandin F2-like compounds are produced in vivo in humans by a non-cyclooxygenase, free radical-catalyzed mechanism. Proc Natl Acad Sci U S A 1990; 87: 9383-7.

29. Basu S. Isoprostanes: novel bioactive products of lipid peroxidation. Free Radic Res 2004; 38: 105-22.

30. Helmersson J, Vessby B, Larsson A, Basu S. Association of type 2 diabetes with cyclooxygenase-mediated inflammation and oxidative stress in an elderly population. Circulation 2004; 109: 1729-34.

31. Gopaul NK, Anggard EE, Mallet AI, Betteridge DJ, Wolff SP, Nourooz-Zadeh J. Plasma 8-epi-PGF2 alpha levels are elevated in individuals with non-insulin dependent diabetes mellitus. FEBS Lett 1995; 368: 225-9.

32. Helmersson J, Larsson A, Vessby B, Basu S. Active smoking and a history of smoking are associated with enhanced prostaglandin $\mathrm{F}$ (2alpha), interleukin-6 and $\mathrm{F}(2)$-isoprostane formation in elderly men. Atherosclerosis 2005; 181: 201-7.

33. Morrow JD, Frei B, Longmire AW, Gaziano JM, Lynch SM, Shyr Y, et al. Increase in circulating products of lipid peroxidation (F2-isoprostanes) in smokers. Smoking as a cause of oxidative damage. N Engl J Med 1995; 332: 1198-203.

34. Dragsted LO, Pedersen A, Hermetter A, Basu S, Hansen M, Haren GR, et al. The 6-a-day study: effects of fruit and vegetables on markers of oxidative stress and antioxidative defense in healthy nonsmokers. Am J Clin Nutr 2004; 79: 1060-72.

35. Freese R, Alfthan G, Jauhiainen M, Basu S, Erlund I, Salminen I, et al. High intakes of vegetables, berries, and apples combined with a high intake of linoleic or oleic acid only slightly affect markers of lipid peroxidation and lipoprotein metabolism in healthy subjects. Am J Clin Nutr 2002; 76: 950-60.

36. Block G, Dietrich M, Norkus EP, Morrow JD, Hudes M, Caan B, et al. Factors associated with oxidative stress in human populations. Am J Epidemiol 2002; 156: 274-85.

37. Sanchez-Moreno C, Cano MP, de Ancos B, Plaza L, Olmedilla B, Granado F, et al. High-pressurized orange juice consumption affects plasma vitamin $\mathrm{C}$, antioxidative status and inflammatory markers in healthy humans. J Nutr 2003; 133: 2204-9.

38. Basu S. Carbon tetrachloride-induced lipid peroxidation: eicosanoid formation and their regulation by antioxidant nutrients. Toxicology 2003; 189: 113-27.

39. Helmersson J, Basu S. F(2)-isoprostane and prostaglandin $\mathrm{F}(2$ alpha)metabolite excretion rate and day to day variation in healthy humans. Prostaglandins Leukot Essent Fatty Acids 2001; 65: 99-102.

40. Richelle M, Turini ME, Guidoux R, Tavazzi I, Metairon S, Fay LB. Urinary isoprostane excretion is not confounded by the lipid content of the diet. FEBS Lett 1999; 459: 259-62.

Cecilia Nälsén
Clinical Nutrition and Metabolism
Department of Public Health and Caring Sciences
Uppsala University
Uppsala Science Park
SE-75I 85 Uppsala, Sweden
Tel: +46 I8 61 I 7968
Fax: +46 I8 6II 7976
E-mail: cecilia.nalsen@pubcare.uu.se

